International Journal of Child, Youth and Family Studies (2012) 2 \& 3: 272-283

\title{
BECOMING-MUSIC: A DESCRIPTION OF AN IMPROVISATIONAL MUSIC THERAPY OUTREACH APPROACH
}

\section{Jeff Smith}

\begin{abstract}
The following paper is a description of a music therapy outreach program that drew upon the philosophical work of Gilles Deleuze and Felix Guattari, narrative therapy, and response-based practice to provide a creative anti-oppressive service to under-housed youth living in Coast Salish and Straight Salish territory (more commonly advertised as Victoria, British Columbia). The author provides examples from his work with a composite character called Pete.
\end{abstract}

Keywords: music therapy, Deleuze and Guattari, outreach, narrative therapy, responsebased practice

Acknowledgements: I acknowledge the tireless radical youth work of Betty Zimmermann and Travis Letondre who ran the "Y-Van", which was a mobile selfreferral hub for youth who did not access office-based social services. I also acknowledge the young nomads who invited me into many creative and thought-provoking interactions. Thanks to Vanessa Vondruska for her well-crafted questions about an earlier draft of this manuscript. Finally, I appreciate the feedback from the anonymous reviewers who contributed to a more succinct and philosophically congruent description of the work.

Jeff Smith, MA, MTA is a music therapy faculty member at the Victoria Conservatory of Music, 900 Johnson Street, Victoria, British Columbia, Canada, V8V 3N4.

Email: galvin@uvic.ca 
International Journal of Child, Youth and Family Studies (2012) 2 \& 3: 272-283

I love everything that flows, everything that has time in it and becoming. That brings us back to the beginning where there is never end. (Henry Miller, p. 232)

In this article, I discuss my engagement of music therapy outreach work with an underhoused youth living in Coast Salish and Straight Salish territory (more commonly advertised as Victoria, British Columbia). I begin by situating the practice of therapy in its dominant modernist location and then describe how the practice of outdoor musical improvisation allowed for connections outside of dominant psychological understandings of problems, and provide an example from my work with a composite youth called Pete. To exemplify this process, I provide a description of how improvised music connected Pete and me in an outdoor environment. To facilitate a disruption of popular forms of institutional power and knowledge in my music therapy work, such as normative discourses of "helping” as psychological and clinical, I experimented with concepts and practices from outside the traditional music therapy, counselling, and child and youth care canons.

I draw upon the work of French philosopher Gilles Deleuze and post-Lacanian psychiatrist Felix Guattari (1996) to describe how our interactions were affected by the unknown (i.e., when a sound or person, etc. exceeds our expectations) and prefabricated systems (i.e., music theory, popular music, therapeutic ideology). I then introduce narrative therapy and response-based practice as frameworks that guide my therapeutic conversations with young people who are responding to life-altering problems.

\section{The Evidence Base}

Social psychologist Ken Gergen (2007) states: "When science attempts to share its knowledge with the public, to influence policy issues, and to sell merchandise (such as psychological tests, books, educational programs), we confront significant issues of cultural concern” (p. 7). Take, for example, former American Psychological Association (APA) president Ronald Levant's (2005) call for "evidence-based practice”, as defined by the Institute of Medicine (IOM). Evidence-based practice (EBP) is a "treatment" that works better than a placebo or "treatment as usual” in two or more studies (Duncan \& Miller, 2006). We see the power of science as discourse when we consider the findings from Wampold's (2001) massive meta-analysis of psychotherapy, which showed that while cognitive behavioural therapists (CBT) cited 15 studies showing a therapeutic advantage for CBT (constituting an evidence-based practice), there were 2,095 studies that showed no difference between CBT and other approaches.

Michel Foucault's (2000) analysis of social science offers a detailed map of how power is embedded within the history of human knowledge through practices that are linked with institutions, economic requirements, and the politics of social regulation. The hegemony of therapeutic approaches like CBT may owe more to the institutional, economic, and political currency of evidence-based discourse than to what researchers actually found. Support for revisions to the dominance of evidence-based practice in therapeutic interactions stresses the 
International Journal of Child, Youth and Family Studies (2012) 2 \& 3: 272-283

need for consistent client consultation about the direction of therapy (Duncan, Miller, \& Sparks, 2004; Duncan \& Sparks, 2007; Prochaska, Norcross, \& DiClemente, 2006).

\section{Street Jams}

Pete and I met in a territory established by the presence of a small outreach team comprised of two paid employees, youth volunteers, and their graffiti-adorned outreach vehicle. The outreach vehicle provided a temporary gathering place for young people to receive support from trusted adults, to access material resources (i.e., food, condoms, articles of clothing), to provide one another with peer support, and to share insider knowledge about places to sleep, bad drugs, dangerous people, and culturally relevant events. Moreover, this mobile territory also served as an entrance to social service structures such as health care clinics, mental health support, addiction counselling, and information about housing.

My connection to this mobile territory provided unique opportunities to enter the rhizome of youth subculture (Skott-Myhre, 2009). The rhizome is a horizontal plant stem, usually growing underground, that sends out roots and shoots from its nodes. It is difficult to track the origin of a rhizome because outgrowths move in every direction. For the purposes of this article, I use the concept of the rhizome in two ways. First, it can be understood structurally as the social underground that is constantly being recreated by a diverse community of young people often referred to as "street involved" or "at-risk" and, second, it can be understood analytically in relation to the sonic outgrowths from the musical improvisations that I took part in.

During my first interaction with Pete, I attempted to build rapport by making casual conversation, by saying "hello" and asking "how are you doing?" to which Pete replied with a nod. I continued:

1. Jeff: "Where are you from?"

2. Pete: "Here and there."

3. Jeff: "Oh, so you are more transient at the moment."

4. Pete: "No I think I still feel a pulse.” (looks at other youth who laugh and look away) "Fucker."

6. Jeff: (silence)

7. Pete: (begins to make a guttural sound with his voice and to play some dissonant notes on his guitar while staring into Jeff's eyes)

8. Jeff: (joins in tentatively by adding a natural harmonic)

This interaction is an example of how youth produce new forms of relating by speaking in what Deleuze and Guattari (1996) describe as secret languages, which are processes of creating a language within a language, by inviting continuous variation (e.g., transient means death?) using both linguistic and non-linguistic elements.

My unintended contribution to the emergence of these languages occurred when I attempted to code Pete's lifestyle as "transient" and he and his friends resisted in ways that were productive, yet unknown to me. Working with people who do not have access to middle-class social privileges, such as stable housing or post-secondary education, requires one to reconsider 
the classist assumptions that accompany training in "interpersonal" and "non-violent" forms of communication. Rather than engaging in a struggle against this young man - for example, I call Pete a name (i.e., transient), he calls me a name (i.e., "fucker”), I treat him according to a popular clinical category (i.e., oppositional defiant), he calls me out, I call the police - I viewed Pete's response as useful feedback (“don’t try to classify my lifestyle, fucker”) and his guitar work and death metal growl as an invitation into a sonic space where we could play out our differences. By "play out" I do not mean we were able to overcome them; on the contrary, what we produced emerged from our engagement with difference. I was able to contribute more intentionally by letting go of the desire for shared forms of meaning making (i.e., any attempt to explain what I meant by transient, or to extract an apology from Pete for swearing at me), which made way for style to emerge from our differences, that is, our unique ways of knowing, speaking, moving our bodies to sound, playing guitar, and singing.

As an outsider to the alternative forms of conduct (i.e., going from town to town, living in squats, making concealed weapons, trading sex with pedophiles for money, drugs, or a place to sleep) engaged in by young people who have limited resources to respond to life-threatening issues (i.e., poverty, homelessness, discrimination, ongoing colonialism, gendered violence, and inadequate health care), I view myself as a visitor while simultaneously attempting to offer contributions in a non-oppressive way. This process is successful when fragments of popular culture (psychology, music therapy, and popular musical forms) are assembled with alternative culture (free improvisation, anti-oppressive practice, hardcore punk, and death metal) to produce new forms of relating that allow for the affirmation of life and expressions of dignity.

My encounters with Pete reminded me that social regulations, for example social norms like my belief that human interactions begin with verbal communication, are fragile and can be broken in the pursuit of forging new connections. My engagement with Pete's non-verbal offer to improvise was an invitation into the rhizome, which, once underway, engaged other voices and opportunities for creation. Pete started with a growl, which elicited a musical response from me. Then another youth joined in, adding a vocalization, linking to another entrance that I responded to with my voice and Pete with another note on the guitar. Each new entrance (sound) modified the territory, and the shared creative endeavour established new sonic territories. The de-centring effect of these movements of mutual transformation can be shocking to those of us who have been trained to plan and document sessions according to a therapeutic milieu prescribed by regulating bodies such as accreditation boards, peer reviewed journals, postsecondary schools, social service agencies, and other institutions.

These openings to the rhizome allowed for improvisation, or what Deleuze and Guattari call lines of flight, to emerge from outdated or unhelpful modes of being, such as normative clinical practices of interacting and documenting/coding those interactions. Hans Skott-Myhre (2009) defines a line of flight as a creative act in which one escapes the confines of prescribed ways of being to establish a new territory or "identity". He writes about hip-hop, street punks, and traditional skinheads (non-racist skins) as youth subcultures that arose as creative responses to capitalism and the mainstream marketing of youth identities. These new identities in flight are connected to various modes of living, such as freestyle rapping, slam dancing, busking, and protesting in diverse ways against a system that categorizes and totalizes. These identities are 
International Journal of Child, Youth and Family Studies (2012) 2 \& 3: 272-283

temporal and once youth subcultures are categorized and totalized, which is an inevitable result of living in the era of global capitalism, creative nomads will have already moved on.

The creative therapeutic encounter provides opportunities to establish safety, honour, and dignity by avoiding the kind of unsolicited advice-giving endemic to helping work, which amounts to an unspoken code in the helping professions. Nick Todd and Allan Wade (1994) refer to this as the colonial code of relations:

1. I am proficient

2. You are deficient, therefore I have the right to

3. Fix you, diagnose you, change you, intern you

4. For your own good

We are then, under the premise of evidence-based practice, justified to proceed with popular interventions. To avoid perpetuating the colonial code of relations and the truncation of flight through oppression, I have found it helpful to reflect upon Foucault's introduction to Deleuze and Guattari’s (2008) Anti-Oedipus: "How does one keep from becoming fascist, even (especially) when one believes oneself to be a revolutionary militant? How do we rid our speech and our acts, our hearts and pleasures, of fascism? How do we ferret out the fascism that is ingrained in our behavior?” (p. xv). My collaborations with youth are more effective when I engage in an ongoing analysis of my institutional positions of power, which gives me an understanding of how, why, and when I orient to power in my work. I have become more observant of how people respond to my actions and, when necessary, I attempt to make amends for perpetrating oppression in my interactions with young people.

When I recognize or am held accountable to my misuses of power - or what Vikki Reynolds calls “replicating dominance” (personal communication, March 13, 2011), that is, providing unsolicited advice, making psychological assumptions, misinterpreting a young person's intentions or lifestyle, promoting heteronormativity, and so on - and apologize for my indiscretions, I am better able to retain connections with youth who are wary of professionals that live outside of their communities.

When a youth takes flight from our professional attempts to code behaviour and solve their problems, we have an opportunity to back off and allow for the escape. We might seek ways to collaborate in the flight process. Facilitating opportunities for non-oppressive youth/adult interactions not only allows for the extension of lines of flight, but may also provide a crucial collaborative context to be an ally to young people who would benefit from a more formal therapeutic arrangement or further structural support. We can use our institutional positions of power and interdisciplinary connections to advocate for social services such as housing, prevention and harm-reduction measures, and recovery beds when those services are available ${ }^{1}$.

${ }^{1}$ Keep in mind that in 2007, over 1,242 people were unable to secure permanent housing (Victoria Cool Aid Society, 2007). 
International Journal of Child, Youth and Family Studies (2012) 2 \& 3: 272-283

\section{Arborescent Tracings}

Many language-dominated models of interaction are based on the idea that we have the world on one hand, and sign systems on the other. The idea that the word (sign system) represents reality "out there" (i.e., behaviourism) or "in here" (i.e., psychodynamic and cognitive behavioural approaches) is a commonly held assumption in the helping professions. Deleuze and Guattari (1996) argue that the representational use of language as a mirror of reality is actually a practice of “... receiving, and transmitting order-words” (p. 76) and that social norms and cultural rules are regulated through "order words", which are statements that are linked to particular social obligations. For example, in therapy these obligations define what can be recognized as normal (i.e., rational/coherent speech) and abnormal (i.e., irrational thoughts or incoherent speech). These clinical obligations are then used in a way that pathologizes alternative subjectivities via dominant clinical formulations.

Deleuze and Guattari (1996) use the term “arborescent” to describe the modern tendency to value a unitary and stable identity that is connected to a root, which is like the one true self, or core truth, that exists beneath the surface. The tracing of the arborescent is already complete, and objects of interest are inserted into its prefabricated reality. For example, arborescent tracings are like the clinical diagnoses and accompanying discourses of dysfunction that were applied to some of the young musical people that I met during my outreach work downtown.

Representatives of the mental health system often misperceive responses to poverty, homelessness, racism, homophobia, violence, harassment, and exploitation as symptoms of personal disorder. Psychiatric labels such as borderline personality, oppositional defiant disorder, and attention deficit hyperactivity disorder are what narrative therapists, drawing upon anthropologist Clifford Geertz, call thin descriptions of people's lives (White \& Epston, 1990; Madigan, 2011). These descriptions are problematic when young people's complex relational and contextual experiences are ignored or misinterpreted because they do not fit the arborescent structures that are constructed by truth-making bodies, such as the American Psychological Association. When the actions of youth are interpreted through psychological discourses and diagnostic criteria, and our professional responses are "evidence-based" and apolitical as opposed to contextual and creatively liberating, we confront issues of significant ethical concern.

Music therapists are well positioned to engage creatively with youth in the ongoing construction of new and preferred identities, and we have unique opportunities to engage in multiple ways of viewing and performing health, community, and justice. My attempt to work within a socially just framework, by remaining open to encounters with diversity and difference, has been transformative.

\section{Improvisation is Immanent}

The concept of immanence provides an alternative to the transcendent linguistic system that fails to recognize difference as a productive resource. Immanence is a concept that Deleuze (1990) borrowed from Spinoza to argue that there are no transcendent or external causes for the world, but rather that life produces life. His analysis is focused on how materials are used to produce something new. Colebrook and Bennett (2009) apply this concept to music and 
challenge the notion of theory as a philosophical or literary movement that is applied to the performance of music, suggesting instead that we have theory because we always already have musicality itself. Deleuze and Guattari (1996) describe the ontology of music as the refrain or rhythm that precedes more formal linguistic systems. In other words, music came first. An understanding of the immanence of music allows one to conceive of musical bodies (i.e., musicians, instruments, notes, and so on) as an interpenetration of the human and non-human, a process of informing, bending, composing, and escaping notation and music theory. This description of music as immanent has implications for practices of improvisational music therapy.

The rhizome is a multiplicity that is always in a process of becoming. Corbett (1994) posits that the rhizome is synonymous with improvised music and rejects the idea that improvisation is an act of self-expression, arguing instead that improvisation is the product of assemblage, which is the creative process that occurs when multiple bodies (i.e., musicians and sounds) collide. These bodies are machined together with different bodies (such as instruments) during a performance to create new configurations. To describe this process is to engage in a cartographic study of sonic tangles. The cartography of an improvisation can be thought of as a mapping process that is continually altered in relation to the changing landscape of sound. The process of mapping a collective improvisation requires one to understand improvisation as an open-source production in which anyone or anything can plot a line on it.

This is of special importance when discussing musical engagements in public spaces ${ }^{2}$, which are subject to multiple sounds and events that arrive from outside to inform a musical event. For example, while working downtown one evening I was involved in a collective improvisation when a shovelhead engine, propelling a Harley-Davidson along Douglas Street (a downtown thoroughfare), became part of the orchestra drowning out our temporarily established tonal center. The roar was soon replaced by a seagull, which allowed us to re-territorialize the sidewalk in the key of A-minor. Other examples of the influence of the "outside” include tempo changes that were informed by the footsteps of tourists, shouts of recognition from across the street, interpretive dance moves, dirty looks, nods of approval, sirens, and screeching tires. It is only in the moment of a musical event that an improvisation can exemplify the ever changing, immanent, and perpetual becoming of reality. When the music ends, so does that moment of becoming-music. We may as musicians, audiences, therapists, and/or researchers attempt to grasp the vestiges of an event through theoretical musings and meaning-making practices (such as I have done in the writing of this paper), however due to the temporal nature of everything this act inevitably falls short, resulting instead in arborescent formulations that envelop, simplify, and signify the multitude that constitutes any event. We can then draw upon those materials in the making of new events and sonic territories.

${ }^{2}$ While the Homeless Needs Survey (Victoria Cool Aid Society, 2007) counted 1,242 homeless or under-housed people in Victoria, public spaces in "the Garden City" are becoming increasingly privatized and patrolled. The sanctions against homeless people in the form of heckling, harassment, violence, economic penalties (in the form of by-law tickets), and arrest, are implemented to enforce socalled public order and safety. 
International Journal of Child, Youth and Family Studies (2012) 2 \& 3: 272-283

\section{Stories of Victory}

Skott-Myhre (2009) declares that the power of the minority, of the "other" (the oppressed and impoverished), can be realized when we draw upon the residue of past struggles for equity, dignity, and liberation. I witnessed this power in Pete who shared stories about the incomplete revolutions of his past. For example, he once described a time when he played the acoustic guitar so loud that he drowned out the voices that had been torturing him that day, only to be interrupted by a security officer who called it noise and then accused Pete of loitering. Pete's attempts to reason with this man were met with hostility and the police were called. Mental health is not promoted by colonial practices that discourage the equal use of "public" space, for instance when Pete's creative practice of interrupting the mean voices with music is counteracted in the name of public security. Our ensuing discussion about Pete's responses to this act of oppression was informed by response-based practice, which is "based on the observation that whenever people are badly treated, they resist” (Wade, 1997, p. 23). We explored the history of Pete's musical expressions and acts of resistance to the oppressors that he faces as a young homeless "street musician”.

In addition to being mistreated by adults on the street, Pete had been diagnosed by professionals with words that were used to categorize him in clinical settings, coding his identity as schizophrenic, oppositional defiant, and depressed. The anthropologist and social scientist Gregory Bateson stated that the language of a person experiencing schizophrenia is appropriated, interpreted, and "over-coded" by the dominant culture based on the positioning of coder (the therapist) and coded (client/patient), without investigating the full local meaning (as cited in Skott-Myhre, 2009). What are the costs when we privilege clinical naming practices and rely on the interventions of modern psychology rather than people's own descriptions of their problems and the co-construction of local solutions? Narrative therapist Stephen Madigan (2007) states:

Professional stories written and told about the person - to the person prescribed and to others - maintain the powerfully pathologized plot, rhetorically embed the problem name (and personal life), and assist in piecing together states of despair... For the person looking for help and change, the naming and writing process of therapy used in North America can be both confusing and traumatic. (p. 179)

While my use of improvisational music has facilitated creative and relational forms of connection it has been important for me to consider the framework I orient to during therapeutic conversations. As a music therapist committed to socially just mental health practices, I draw from narrative therapy and response-based frameworks to explore and contextualize young people's creative acts of resistance against oppression and life-altering problems. These approaches offer opportunities to subjugate dominant psychological ideas about people experiencing difficulties and privilege locally relevant explanations about problems and the kind of responses that contribute to living preferred lives. In Pete's case, we explored the directions that he assigned to the multiple voices, which were fundamental to our ongoing musical and verbal interactions. Rather than perceiving Pete's multiplicity of moods and discursive twists as disturbing, and then invoking the arborescent by ignoring, distorting, or appropriating their meaning, I did my best to remain with the tension of the constant movements. Through my questions, guided by narrative therapy (White \& Epston, 1990), I learned about Pete's unique 
International Journal of Child, Youth and Family Studies (2012) 2 \& 3: 272-283

relationship to "the voices" and was able to align with him as we co-investigated strategies that he had used to give him an advantage over the "mean ones". As we had mapped the recent history of the mean voices, we found that they were often connected to material concerns such as housing, mental health support (or the dearth of it), violence, and prescription and nonprescription drug use.

\section{Conclusion}

By entering the rhizome in our creative work with youth, we become engaged outside of the mainstream and are afforded opportunities to add new routes to the map of our lives as practitioners. We may start in a well-defined territory, such as a common theory of communitybased music therapy (Baines, 2003; Stige, 2002), or strum the chords of a well-known song such as Wish You Were Here by Pink Floyd. However, if we allow ourselves to move beyond the confines of the arborescent (our theory, our world view, the correct way to play a song) and allow for movement outside of the chord/harmonic structure of the song, we engage in a process of becoming. This process is integral to my conceptualization of improvisational music therapy as a decolonizing form of collaborative expression. I find this endeavour to be challenging, and an especially important consideration when working with people who are responding to legacies of residential school imprisonment, prison history, psychiatric hospitalization, and other contemporary forms of forced institutionalization.

Like the process of flight and capture mentioned previously, the rhizome is constantly being re-territorialized (mapped as familiar/arborescent), de-territorialized (disrupted), and then re-territorialized again (Deleuze \& Guattari, 1996). Case in point: Improvised music occurs through the establishment or territorialization of tonal or rhythmic centres that are then abandoned, or de-territorialized, by one or more musicians during a group session, leading to new musical landscapes. This allows youth and music therapists to construct new ways of being relational, creative, and expressive in the world, which are not predetermined by normalized categories of music-making (which often excludes untrained or self-taught musicians). The rhizome is not impermeable to lines of order and control (arborescent) because it connects to everything, including regimes of dominant power. This open system allows access to everyone, providing people of social and economic privilege working within arborescent structures like the Victoria Conservatory of Music (VCM), opportunities to connect with youth who do not identify themselves in terms of the dominant culture.

Skott-Myhre (2009) writes that youth produce themselves in the cracks and fissures of the dominant culture by, for example, recording an original punk rock song, or spitting a freestyle rap in a classical music school. Providing opportunities for economically marginalized youth to participate in programming at a community music school led to new musical, relational, and recording/production experiences for youth who spend much of their time in squats, parks, roadsides, in and out of foster care, and recovery homes. Despite good attendance, a high number of referrals from community partners, and positive outcomes (for example, music recordings and testimonials of participants and community partners), the music therapy outreach project did not receive further funding. One afternoon after I shared the news with a regular program participant, she picked up a guitar and played a familiar chord pattern to accompany her raspy voice that belted out the following lyrics: 
International Journal of Child, Youth and Family Studies (2012) 2 \& 3: 272-283

While they're standing in the welfare lines

Crying at the doorsteps of salvation

Wasting time in the unemployment lines

Sitting around waiting for a promotion

Poor people gonna rise up

And get their share

Poor people gonna rise up

And take what's theirs (Chapman, 1988) 
International Journal of Child, Youth and Family Studies (2012) 2 \& 3: 272-283

\section{References}

Baines, S. (2003). A consumer-directed and partnered community mental health music therapy program: Program development and evaluation. Voices: A World Forum for Music Therapy, 3(3). Retrieved from https://normt.uib.no/index.php/voices/ article/view/137/113

Chapman, T. (1988). Talking about a revolution. On Tracy Chapman [CD]. Hollywood, CA: Elektra/Asylum Records.

Colebrook, C., \& Bennett, D. (2009). The sonorous, the haptic and the intensive. New Formations, 66 (spring, 2009), 68-80.

Corbett, J. (1994). Extended play: Sounding off from John Cage to Dr. Funkenstein. Durham, NC: Duke University Press.

Deleuze, G. (1990). Expressionism in philosophy: Spinoza. New York: Zone Books.

Deleuze, G., \& Guattari, F. (1996). A thousand plateaus: Capitalism and schizophrenia (Vol. 2). Minneapolis: University of Minnesota Press. (Original work published 1980)

Deleuze, G., \& Guattari, F. (2008). Anti-Oedipus: Capitalism and schizophrenia (Vol. 1). Minneapolis: University of Minnesota Press. (Original work published 1972)

Duncan, B., Miller, S., \& Sparks, J. (2004). The Heroic client: A revolutionary way to improve effectiveness through client-directed, outcome informed therapy. San Francisco: Jossey-Bass.

Duncan, B., \& Miller, S. (2006). Evidence based practice: Talking points. Treatment manuals do not improve outcomes. In J. Norcross, R. Levant, \& L. Beutler (Eds.), Evidence based practices in mental health. Washington, D.C.: APA Press.

Duncan, B., \& Sparks, J. (2007). Heroic clients, heroic agencies: Partners for change. Chicago: ISTC Press.

Foucault, M. (2000). The subject and power. In J. Faubion \& P. Rabinow (Eds.), Power: Essential works of Foucault (pp. 326-348). New York: The New Press.

Gergen, K. (2007). The self: Colonization in psychology and society. In M. Ash \& T. Sturm (Eds.), Psychology's territories: Historical and contemporary perspectives from different disciplines (pp. 149-168). New York: Routledge. Retrieved February 12, 2009 from http://www.swarthmore.edu/x20607.xml

Levant, R. (2005). Evidence-based practice in psychology. APA Online, 36(2), 5. Retrieved April 2, 2009 from http://www.apa.org/monitor/feb05/pc.html 
International Journal of Child, Youth and Family Studies (2012) 2 \& 3: 272-283

Madigan, S. (2007). Anticipating hope within written and naming domains of despair. In C. Flaskas, I. McCarthy, \& J. Sheehan (Eds.), Hope and despair in narrative and family therapy: Adversity, forgiveness and reconciliation (pp. 100-112). Hove, UK: Brunner-Routledge.

Madigan, S. (2011). Narrative therapy (Theories of psychotherapy). Washington, DC: APA Press.

Miller, H. (1982). Tropic of cancer. New York: Grove Press.

Prochaska, J., Norcross, J., \& DiClemente, C. (2006). Changing for good. New York: Collins.

Skott-Myhre, H. (2009). Youth and subculture as creative force: Creating new spaces for radical youth work. Toronto: University of Toronto Press.

Stige, B. (2002). Culture-centered music therapy. Gilsum, NH: Barcelona Publishers.

Todd, N., \& Wade, A. (1994). Domination, deficiency and psychotherapy. Calgary Participator, 4(1) (fall, 1994), 37-46.

Victoria Cool Aid Society. (2007). Homeless needs survey, 2007: Housing first - plus supports. Retrieved from http://www.coolaid.org/publications/ HNS_Final_Report_2007.pdf

Wade, A. (1997). Small acts of living: Everyday resistance to violence and other forms of oppression. Contemporary Family Therapy, 19(1), 23-39.

Wampold, B. E. (2001). The great psychotherapy debate: Models, methods, and findings. Hillsdale, NJ: Lawrence Erlbaum Associates.

White, M., \& Epston, D. (1990). Narrative means to therapeutic ends. New York: Norton. 